\title{
How responsiveness from a communication partner affects story retell in aphasia: Quantitative and qualitative findings
}

Tyson G. Harmon

Brigham Young University, tyson_harmon@byu.edu

Adam Jacks

University of North Carolina at Chapel Hill

Katarina L. Haley

University of North Carolina at Chapel Hill

Antoine Bailliard

University of North Carolina at Chapel Hill

Follow this and additional works at: https://scholarsarchive.byu.edu/facpub

Part of the Other Communication Commons, and the Speech and Rhetorical Studies Commons

\section{Original Publication Citation}

Harmon, T. G., Jacks, A., Haley, K. L., \& Bailliard, A. (2019). How responsiveness from a communication partner affects story retell in aphasia: Quantitative and qualitative findings. American Journal of Speech-Language Pathology, Advance online publication. https://doi.org/ 10.1044/2019_AJSLP-19-0091

\section{BYU ScholarsArchive Citation}

Harmon, Tyson G.; Jacks, Adam; Haley, Katarina L.; and Bailliard, Antoine, "How responsiveness from a communication partner affects story retell in aphasia: Quantitative and qualitative findings" (2019). Faculty Publications. 3673.

https://scholarsarchive.byu.edu/facpub/3673

This Peer-Reviewed Article is brought to you for free and open access by BYU ScholarsArchive. It has been accepted for inclusion in Faculty Publications by an authorized administrator of BYU ScholarsArchive. For more information, please contact ellen_amatangelo@byu.edu. 


\title{
How responsiveness from a communication partner affects story retell in aphasia: Quantitative and qualitative findings
}

\author{
Tyson G. Harmon ${ }^{\mathrm{a}}$ \\ Adam Jacks \\ Katarina L. Haley \\ Antoine Bailliard ${ }^{\mathrm{c}}$
}

\author{
${ }^{a}$ Department of Communication Disorders, Brigham Young University, Provo, UT \\ ${ }^{b}$ Division of Speech and Hearing Sciences, Department of Allied Health Sciences, University of \\ North Carolina, Chapel Hill, NC \\ ${ }^{\mathrm{c} D i v i s i o n}$ of Occupational Science and Occupational Therapy, Department of Allied Health \\ Sciences, University of North Carolina, Chapel Hill, NC
}

RUNNING HEAD: EFFECT OF PARTNER RESPONSIVENESS IN APHASIA DISCOURSE

Please address correspondence to:

Tyson G. Harmon

Department of Communication Disorders

158 John Taylor Building

Brigham Young University

Email: Tyson Harmon@byu.edu

Telephone: 801-422-1251

Keywords: aphasia, communication, stroke, fluency 


\begin{abstract}
Purpose: Because people with aphasia frequently interact with partners who are unresponsive to their communicative attempts, we investigated how partner responsiveness affects quantitative measures of spoken language and subjective reactions during story retell.
\end{abstract}

Method: A quantitative and a qualitative study were conducted. In study 1, participants with aphasia and controls retold short stories to a communication partner who indicated interest through supportive backchannel responses (responsive) and another who indicated disinterest through unsupportive backchannel responses (unresponsive). Story retell accuracy, delivery speed, and ratings of psychological stress were measured and compared. In study 2, participants completed semi-structured interviews about their story retell experience, which were recorded, transcribed, and coded using qualitative analysis software.

Results: Quantitative results revealed increased psychological stress and decreased delivery speed across all participant groups during the unresponsive partner condition. Effects on delivery speed were more consistent for controls than participants with aphasia. Qualitative results revealed that participants with aphasia were more attuned to unresponsive partner behaviors than controls and reported stronger and more frequent emotional reactions. Partner responsiveness also affected how PWA perceived and coped with the communication experience.

Conclusion: Combined quantitative and qualitative findings suggest that while unresponsive communication partners may not have robust effects on spoken language, they elicit strong emotional reactions from people with aphasia and affect their communication experience. These findings support the need for communication partner training and suggest that training people with aphasia on emotion regulation or relaxation techniques may help assuage their anxiety during socially challenging everyday communication and increase social participation. 


\section{Introduction}

People with chronic aphasia are often excluded from social circles and can become isolated. They have been shown to lose friendships, interact with fewer communication partners than their neurologically healthy peers, and experience general loneliness (Davidson, Howe, Worrall, Hickson, \& Togher, 2008; Parr, 2007). This social isolation results from general avoidance of social situations (Parr, 2007), including challenging everyday communication contexts (Baylor, Burns, Eadie, Britton, \& Yorkston, 2011). Even when they do attend events or social gatherings, people with aphasia (PWA) report withdrawing by trying to fade into the background and limit their talking (Baylor et al., 2011, p. 275). One factor that contributes to this avoidance and withdrawal is the attitudes and behaviors of communication partners (Baylor et al., 2011; Croteau \& Le Dorze, 2001; Garcia, Barrette, \& Laroche, 2000; Le Dorze, SaloisBellerose, Alepins, Croteau, \& Hallé, 2014). The present article investigates how the responsiveness of a communication partner affects both communicative performance and the communication experience for people with aphasia. We define communication partner responsiveness as the interest or engagement demonstrated by a listener through backchannel responses (e.g., eye contact, body posture, facial expressions; Heinz, 2000).

\section{Communication Partner Responsiveness}

Communication partner responsiveness has long been of interest in aphasia because of the role it can play in supporting communication. Good communication partners respond to communicative attempts of people with aphasia by demonstrating a listening attitude through appropriate backchannel responses such as acknowledgement tokens (utterances that acknowledged receipt of contributions from the person with aphasia such as "mhm" and "I see") and congruent overlap (interpersonal coordination such as synchronous head nods; Simmons- 
Mackie \& Kagan, 1999). But PWA often interact with "poor" communication partners who are unresponsive to their communicative attempts (Dalemans, de Witte, Wade, \& van den Heuvel, 2010; Parr, 2007). For example, they may interact with partners who they perceive to be dismissive, unreceptive, or disengaged and to show signs of annoyance (e.g., sighs, tightening of mouth muscles, shoulder and eye movements; Baylor et al., 2011; Garcia et al., 2000; Skelly, 1975). While communication partners may be unresponsive because they lack education about aphasia (see e.g., Le Dorze et al., 2014), even those with a background in speech pathology report feeling uncomfortable and impatient when hearing PWA talk (Harmon, Jacks, Haley, \& Faldowski, 2016). Dalemans, de Witte, Wade, and van den Heuvel (2010) analyzed qualitative data from daily two-week diary entries and semi-structured interviews completed by 12 people with aphasia and their caregivers. In addition to factors related to knowledge about aphasia, participants revealed that the communication partner's willingness to listen (e.g., by showing patience, talking slowly, and pausing when needed) supported or facilitated their communication. Unfortunately, during the two-week period, participants reported frequent communication between people with aphasia and partners who were impatient, insensitive, lacked empathy, and failed to really listen.

Despite people with aphasia perceiving many of their communication partners as unresponsive, little is known about how this perception affects their spoken language and communicative experiences. Qualitative evidence suggests that unresponsive partners contribute to people with aphasia feeling "frustrated," "isolated," "misunderstood," "ridiculed" in public, left out, ignored, stigmatized, and discouraged during conversations (Baylor et al., 2011; Kagan, 1998; Le Dorze et al., 2014; Parr, 2001; Skelly, 1975). These emotional reactions could lead to 
feelings of stress and subsequent interference in spoken language and communicative life participation.

\section{Stress and Spoken Language}

For healthy adults with no aphasia, partner responsiveness has been shown to increase stress response, which, in turn, reduces speech fluency. Past studies have manipulated partner responsiveness via backchannel responses that indicate interest and engagement: facial expression, eye contact, body posture, etc. (Hilmert, Christenfeld, \& Kulik, 2002; Lepore, Allen, \& Evans, 1993). Using this manipulation method, unresponsive partner feedback has been shown to increase physiological stress response in healthy adults (Lepore et al., 1993; Thorsteinsson \& James, 1999). Experiencing stress also seems to affect spoken language for adults with no aphasia. Buchanan et al. (2014) found that 91 healthy young adults had significantly greater pause time during a stressful speech task (i.e., defending themselves in front of a store manager after being accused of shoplifting) compared with a control task (i.e., summarizing a general interest travel article). These authors also found a correlation between heart rate, cortisol, and pause duration during the final minute of the stressful speech task.

People with aphasia may be more likely to feel stress or anxiety during social communicative interactions than their peers, which has the potential to similarly reduce their speech fluency. Stress response has been investigated using both physiological (i.e., salivary cortisol, heart rate, and skin conductance) and psychological (i.e., self-rated stress or anxiety) measures. Although findings regarding physiological stress response have been equivocal, people with aphasia have consistently reported greater psychological stress when participating in a socially demanding interpersonal communication task (e.g., telling an unfamiliar communication partner about their occupation prior to their stroke; Cahana-Amitay et al., 2015; 
Laures-Gore, Heim, \& Hsu, 2007). In one case study, a participant with mild aphasia performed a free discourse task under typical assessment conditions and when anticipating having to give a speech to a group of experts following the session (i.e., high stress; Cahana-Amitay et al., 2015). The participant produced a greater percentage of extended and filled pauses per utterance in the high stress condition. Despite the suggestion that social stress might affect spoken language and the potential for unresponsive communication partners to induce stress (see e.g., Lepore et al., 1993), we are not aware of any study that has systematically investigated the direct effects of partner responsiveness on psychological stress or discourse production in aphasia.

Given that people with aphasia frequently experience social isolation and often interact with unresponsive partners, it is important to learn how partner responsiveness affects both spoken language and perceptions about the communication experience. This could lead to improved training for people with aphasia and their communication partners. Helping people with aphasia experience communicative exchanges that they perceive as successful is an important goal of therapy and has the potential to increase their life participation (Chapey et al., 2000).

We present two complementary studies that aim to determine how the responsiveness of a communication partner affects spoken language performance, psychological stress, and the communication experience for people with aphasia when retelling a story. Study 1 examined spoken language (content accuracy and delivery speed) and psychological stress quantitatively; study 2 examined participants' subjective perceptions about the communication experience.

Study 1: Effects of Communication Partner Responsiveness on Psychological Stress and Spoken Language 
The primary aim of Study 1 was to determine how communication partner responsiveness affects ratings of psychological stress and measures of spoken language accuracy and speed for people with aphasia. Based on previous findings, we hypothesized that participants would report greater psychological stress and decreased fluency when retelling a story to an unresponsive communication partner (Buchanan, Laures-Gore, \& Duff, 2014; Cahana-Amitay et al., 2015; Lepore et al., 1993). Based on qualitative findings suggesting that people with aphasia react negatively to unresponsive partners (Le Dorze et al., 2014; Parr, 2001; Skelly, 1975), we suspected they would experience greater psychological stress than control participants. We thought that this might lead to even greater spoken language interference for people with aphasia than controls (Cahana-Amitay et al., 2015).

\section{Method}

Participants. Thirty-three people participated in the study (21 with aphasia; 12 controls), which was approved by the University of North Carolina at Chapel Hill (UNC-CH) Institutional Review Board.

Participants with aphasia. Participants with aphasia included 8 males and 13 females. All passed a hearing screening at $40 \mathrm{~dB}$ for $0.5,1$, and $2 \mathrm{KHz}$ or, in the case of two whose hearing was not tested due to an oversight in the protocol, reported normal hearing. All participants passed a vision screening, but three demonstrated a partial loss of their right visual field (A04, A08, A16). All were in the chronic stage of aphasia recovery: at least 19 months post-onset.

Participants with aphasia completed the Western Aphasia Battery Revised (WAB-R; Kertesz, 2006) to evaluate their language, the Geriatric Depression Scale short form (GDS; Yesavage \& Sheikh, 1986) to screen for symptoms of low mood, and the Personal Report of 
Communication Apprehension (PRCA-24; McCroskey, Beatty, Kearney, \& Plax, 1985). The PRCA-24 is a written, 24-item questionnaire that asks participants to rate each statement on a five-point Likert scale from strongly agree to strongly disagree. It has been shown to reliably measure trait-like anxiety associated with real or anticipated interpersonal communication (McCroskey et al., 1985; McCroskey \& Richmond, 1982). When administering this questionnaire to participants with aphasia, investigators presented the written questionnaire, read each question out loud, and verbally verified responses to ensure understanding. Scores and other demographic information are reported in Table 1.

Participants with aphasia were divided into two severity groups (i.e., moderate and mild) based on a WAB-R Aphasia Quotient (AQ) score cutoff of 80: The moderate group included all participants with a score less than 80 (range $=52.1$ to 77.8$)$ and the mild group included all participants with a score greater than 80 (range $=82.8$ to 100.0). Four participants from the mild group scored in the non-aphasic range (i.e., AQ > 93.8). These four participants were included in the study because they all had a history of aphasia, reported continued difficulties with wordfinding in their everyday communication, and were judged by the first three authors to have word-finding errors (e.g., hesitations, circumlocution) during conversation.

Control participants. Control participants included five males and seven females. All completed the Questionnaire to Verify Stroke-free Status (QVSFS; Jones, Williams, \& Meschia, 2001) and reported no history of symptoms related to stroke or other neurological damage. All control participants passed vision and hearing screenings and completed the PRCA-24. Their scores and demographic information are shown in Table 1.

Procedures. Participants completed a narrative discourse task to approximate everyday communication while controlling for content. The stimuli included four stories designed to 
assess narrative production in aphasia (Doyle et al., 1998). These stories were matched for content (i.e., number of words, number of sentences, number of subordinate clauses and mean sentence length) and complexity (i.e., ratio of clauses to T-units, listening difficulty, and number of unfamiliar words) and are comparable to other commonly used discourse elicitation methods (McNeil et al., 2007). Participants were presented with an auditory recording and six sequenced pictures that go along with the story, and subsequently were asked to retell the story without visual or audio support. Each participant practiced the narrative discourse task by telling one of these stories to the investigator before beginning the experiment. The stories were pseudorandomly assigned across the practice retell and experimental conditions to allow for counterbalancing. The order of experimental conditions was also pseudorandomly assigned to control for potential order effects.

Experimental conditions. All participants retold stories to a communication partner who was trained to exhibit backchannel responses that indicated interest and engagement (responsive partner condition) and a communication partner who was trained to exhibit backchannel responses that indicated disinterest (unresponsive partner condition). Before listening to the story, the responsive partner introduced themselves with normal vocal tone, rate, and loudness. For participants with aphasia, the introduction contained a verbal acknowledgement of the participant's competence (Kagan, 1998). Following their introduction, the communication partner listened to the person with aphasia retell the story. While listening, the responsive partner demonstrated good eye contact, positive facial expressions and head nods, an open body posture, and verbal affiliatives (i.e., "mhm," “ok," "I see," etc.; Kagan, Black, Duchan, Simmons-Mackie, \& Square, 2001; Simmons-Mackie \& Kagan, 1999). For an illustration of this condition, see online Supplemental Video S1. 
The unresponsive partner demonstrated opposite behaviors as the responsive partner. During their introduction, the unresponsive partner spoke with a patronizing tone, slow rate, and greater than typical loudness. They did not verbally acknowledge the participant's competence and, when listening to the story, demonstrated poor eye contact, neutral facial expression, and closed body posture. They did not use verbal affiliatives or head nods. For an illustration of this condition, see online Supplemental Video S2.

Both responsive and unresponsive partners entered the room with a mobile phone, which was placed on top of a clipboard. When they sat down they placed the clipboard and phone on the table between them and the participant. The unresponsive partner shifted her attention approximately every 20 seconds. Occasionally, these shifts of attention included checking the time on the phone in front of her. This was done by pressing the home button on the phone screen. The phone was never picked up or moved by either partner. The responsive partner kept the phone in front of her without touching it.

Communication partners and fidelity. Four graduate students in speech-language pathology were trained to demonstrate both responsive and unresponsive behaviors and two were selected as the communication partners for the experiment. Both were female and assisted with the study to fulfill part of their graduate research experience. They were pseudorandomly assigned as the responsive or unresponsive partner for each participant. For participants with aphasia, one student was the responsive partner 10 times and the unresponsive partner 11 times; the other was the responsive partner 11 times and the unresponsive partner 10 times. Each student was both the responsive and unresponsive partner six times for the control group. All story retells were recorded with a Canon Vixia HF R500 camcorder facing the communication partner. 
A student research assistant viewed all video recordings and completed interval coding for each $10 \mathrm{~s}$ segment to check fidelity to the protocol. Introduction and listening segments were coded separately. For introduction segments, the research assistant coded whether the communication partner used a patronizing voice and whether she acknowledged the participant's competence. For the listening segments, the research assistant coded whether eye contact was appropriate or inappropriate, body posture was open or closed, affiliatives (i.e., smiles and head nods) were present or not present, and whether or not the partner had demonstrated a "listening attitude.” Average responsiveness scores were calculated with zero indicating an absence of responsive behaviors and higher numbers $(\max =2$ for introduction segments; $\max =4$ for listening segments) indicating all responsive behaviors present. Communication partners were judged to have equal fidelity with the protocol on both introduction (unresponsive, 0.00 and 0.00; responsive, 2.00 and 1.78) and listening segments (unresponsive, 0.14 and 0.17; responsive, 3.86 and 3.84).

Dependent Variables. The main dependent variables were self-rated psychological stress and story retell performance.

Psychological stress. After each story retell, the communication partner left the room and the investigator re-entered and guided the participants in completing a brief questionnaire to assess psychological stress. The measure consisted of four Likert statements rated from 1 (not at all) to 5 (very much): (1) retelling the story was stressful, (2) retelling the story was pleasant, (3) I felt nervous when retelling the story, and (4) I was calm while retelling the story (see Hilmert et al., 2002). When administered to participants with aphasia, questions were read aloud and responses were verified to ensure that the participant understood and responded appropriately. Prior to analysis, psychological stress questions 2 and 4 were reverse coded so that low numbers 
signified less psychological stress and high numbers indicated greater psychological stress. The four ratings were then averaged to obtain the overall psychological stress score.

Story retell performance. Dependent variables relating to story retell performance included five measures of spoken language: two accounted for content accuracy and three accounted for delivery speed. The five measures were taken from utterance, word, correct information unit (CIU), and disfluency counts.

To analyze content, the first author and a trained undergraduate research assistant first transcribed all samples orthographically in CHAT format. Utterance boundaries were identified as outlined in the CHAT manual (MacWhinney, 2000). Word counts obtained from the computerized language analysis (CLAN) software included all intelligible words except fillers or phonological fragments. Intrarater reliability for word and utterance counts was $r=.99$ and $r=$ .91 respectively; interrater reliability for word counts was $r=.99$ and for utterance counts was $r$ $=.80$. Next, CIUs were counted by the undergraduate research assistant (Nicholas \& Brookshire, 1993). Intrarater and interrater reliability for CIU counts were high $(r=.99)$. Measures of content accuracy included speech productivity (i.e., number of CIUs produced) and speech efficiency (i.e., ratio of CIUs to words).

To analyze speech fluency, disfluent behaviors (i.e., simple repetitions, extended pauses, and filled pauses) were coded in Praat (Boersma \& Weenink, 2014) using acoustic segmentation. Repetitions included sound, syllable, and monosyllabic word repetitions. All pauses or filled pauses equal to or greater than one second were coded as silent or filled pauses. The author and a graduate student research assistant each coded approximately half of the samples for disfluencies then re-coded $20 \%$ of the samples, which were selected randomly. Intrarater reliability was $r>$ .87 for repetition counts and $r>.98$ for pause counts. The first author also coded $20 \%$ of the 
samples that the graduate student had originally coded, which were selected randomly: interrater reliability was $r=.83$ for repetition and $r=.94$ for pause counts. Measures of delivery speed included speech rate (i.e., number of words produced per minute), repetitions (i.e., ratio of sound, syllable and monosyllabic word repetitions per word), and pauses (i.e., ratio of extended and filled pauses per utterance).

Statistical Analysis. All dependent variables were analyzed using two-way mixed effects ANOVAs. Because data distributions for pauses per utterance did not meet the assumption of homogeneity of variance, logarithmic transformations were performed prior to analysis. The two factors were Group (moderate aphasia, mild aphasia, control) as the between-subject factor and Condition (responsive partner, unresponsive partner) as the within-subject factor. Tukey's HSD tests were used to follow up on significant main effects.

Correlational analyses were used to investigate the relationship between communicative apprehension (PRCA-24), psychological stress, and spoken language measures. Visual inspection of the data revealed one outlier in speech productivity from the control group during the responsive partner condition. This outlier was removed prior to analysis.

All statistical analyses were completed using R 3.4.1 (R Core Team, 2017). Mixedeffects ANOVAs were completed on models built using the lme function within the nlme package (Pinheiro, Bates, Debroy, Sarkar, \& R Core Team, 2017) and pairwise comparisons were made on the model using the emmeans package (Lenth, 2017).

\section{Results}

Table 2 presents descriptive statistics for all dependent variables. The three participant groups differed in measures of accuracy (i.e., speech productivity [number of CIUs], efficiency [percent CIUs per word]), and speed (i.e., speech rate [words per minute], repetitions per word, 
pauses per utterance). Significant group differences were observed for all variables and almost all measure and group pairs. In general, accuracy and speed were lowest for participants with moderate aphasia. Their stories were told with less productivity and efficiency, slower speech rate, and more pauses than those told by participants with mild and no aphasia. Participants with moderate aphasia also produced more repetitions than participants with no aphasia; however, no difference in repetitions was found between moderate and mild aphasia groups $(p=.580)$. Participants with mild aphasia were generally faster and more accurate than those with moderate aphasia. They also retold stories with less accuracy and a slower rate of speech than controls, but did not differ in pauses per utterance $(p=.095)$. There were no interaction effects.

In addition to group effects, main effects of Condition were found on two measures of speed, but high individual variability and more consistent effects on the control group were noted. In general, speech rate decreased and pauses per utterance increased in the unresponsive partner condition ( $p=.027 ; p=.016$, respectively). Despite significant main effects, effects on speech rate and pauses per utterance for individual participants varied. Two-thirds (14/21) of PWA and three-quarters (9/12) of control participants decreased their speech rate from responsive to unresponsive partner conditions. Similarly, nearly two-thirds (13/21) of PWA and three-quarters (9/12) of controls increased their pauses per utterance. Individual control participants, therefore, showed more consistent detriments to speed than participants with aphasia, which was contrary to our hypothesis.

Our hypothesis that participants would report greater psychological stress after retelling a story to an unresponsive partner was confirmed, but, similar to effects on story retell speed, this effect was no greater for PWA than controls. Analysis of stress ratings showed a main effect for Condition $(F[1,30]=22.23, p<.001$; see Figure 1), but no Group or interaction effects. 
Correlations between communicative apprehension, psychological stress, and story retell performance are shown in online Supplemental Table S3. A moderate positive correlation was found between communicative apprehension scores and ratings of psychological stress ( $r=$ .475), indicating that participants who generally feel more anxiety associated with communication tended to rate themselves as feeling more stressed after retelling stories. A significant, but weak, negative correlation was found between psychological stress and speech productivity $(r=-.260)$. Weak negative correlations were also found between psychological stress and speech rate $(r=-.230)$ and communicative apprehension and speech productivity $(r=-$ $.231)$.

\section{Discussion}

During everyday communication, people with aphasia interact with partners who vary in their level of responsiveness. Unfortunately, unresponsive partners are common and can contribute to social isolation. The aim of the first study was to understand the effects of communication partner responsiveness on psychological stress and spoken language performance during narrative discourse. Participants reported feeling higher levels of stress when retelling stories in the unresponsive partner condition. Generally, they tended to speak more slowly in this condition, but changes in both speed and accuracy varied among individual participants.

The increased stress reported by all participant groups when retelling stories to an unresponsive partner confirms that this was an emotionally taxing condition. Aphasia therapy may address emotional challenge by targeting emotion regulation or training communication partners. Targeting emotion regulation in aphasia therapy could provide PWA with strategies needed to assuage the stress induced by unresponsive partners (Dickinson, Friary, \& McCann, 
2017; Marshall, Laures-Gore, \& Love, 2018). This may also improve social participation in general by helping PWA reduce feelings of fear and anxiety during other challenging communication situations. Continuing to train communication partners in supportive communication strategies is also important (Kagan, Black, Duchan, Simmons-Mackie, \& Square, 2001; Simmons-Mackie \& Kagan, 1999). In doing so, the effect of subtle backchannel responses should not be overlooked.

In addition to increasing psychological stress, talking to an unresponsive communication partner generally decreased delivery speed across participant groups; however, this effect was more variable for people with aphasia than control participants. High variability in the data may be explained by individual differences in (1) responding to the narrative discourse task in general, (2) reacting to the unresponsive communication partner specifically, or (3) ability to use strategies to cope with stress. First, as suggested by the correlation between communicative apprehension scores and psychological stress ratings, how participants responded to the discourse task regardless of the condition seemed to be affected by personal trait factors related to anxiety associated with communicative interaction.

Second, individual participants might have varied in their specific reaction to the unresponsive communication partner. Some participants seemed attuned to the communication partner behaviors while others seemed indifferent. Study 2 explores these qualitative responses. One variable related to stress and performance is arousal. The Yerkes-Dodson law (1908) suggests a link between performance and arousal such that as arousal reaches a mid-point, optimal performance occurs but when arousal is too low or too high, performance deteriorates. It is likely that some participants' stress led to arousal levels consistent with more optimal performance where others experienced hyperactive neurovisceral activity. One previous study 
found a relationship between physiological stress response and word productivity during a discourse task in aphasia, suggesting that some participants with aphasia persisted throughout the task and spoke more because of increased arousal (Laures-Gore, DuBay, Duff, \& Buchanan, 2010). This same phenomenon may account for the nearly half of participants in the present study who increased their productivity and efficiency when talking with an unresponsive partner.

Third, even when experiencing feelings of stress, individual participants likely differed in how they coped with these feelings (Laures-Gore \& Buchanan, 2015). Even if participants' stress response in the unresponsive partner condition was similar, some may have been better equipped to cope with their reaction. In a previous study, PWA were shown to possess fewer coping resources than their peers with no aphasia-particularly in their self-awareness and ability to relax and control their thoughts during stressful situations (DuBay, Laures-Gore, Matheny, \& Romski, 2011). Such strategies might account for vulnerability or resilience to the effects of stress (Laures-Gore \& Buchanan, 2015) and warrant further investigation.

\section{Study 2: Subjective reactions to responsive and unresponsive communication partners}

In study 2, we explored and categorized the subjective experience of people with moderate or mild aphasia and a control group immediately following the experimental protocol from study 1 . The qualitative methodology allowed us to learn about participants' experience from their own perspective without relying on predetermined categories or researcher assumptions. The aim of study 2 was to explore how PWA react to different levels of communication partner responsiveness. A secondary aim was to characterize differences in the subjective reactions of people with moderate or mild aphasia and control participants.

\section{Method}


We used a qualitative descriptive research design with data derived from semi-structured interviews. Like the quantitative study, the qualitative procedures were approved by the UNCCH Institutional Review Board.

Participants. Participants were the same as those in study 1 with two exceptions. First, one control participant (C02) was not included due to a technical problem with the transcription of his interview. Second, the study included one additional participant with moderate aphasia (A15) who required too much prompting to complete the story retell task, but was able to produce personal narratives in response to conversational prompts provided by the investigator immediately prior to each condition (see Table 1). Although the speech elicitation task was different, we decided to include this participant in study 2 because the responsive and unresponsive partner conditions were identical to what was experienced by the other participants. This resulted in the inclusion of twenty-two PWA (13 female; 9 male) and eleven control (7 female; 4 male) participants.

Procedure. Immediately after study 1 participants completed a semi-structured interview, which began with questions about the overall experience and then proceeded to discuss the responsive and unresponsive partner conditions. Probing question related to participants' feelings and self-evaluations of their performance were also included (see online Supplemental Appendix S4). Consistent with semi-structured interview methodology, the order and wording of questions varied throughout each interview to allow for adaptation to the individual needs of each participant (Britten, 1995).

During the interview, responsive communication strategies were used to ensure comprehension and verify responses. For example, the interviewer used simple sentences and gestures, provided paper and pen for graphic and written communication options, and 
occasionally paired verbal questions with written choices (see Kagan, 1998). When paper and pen were used to support communication, these were collected as data and referred to by coders during analysis as supplements to interview transcripts. Previous studies have used similar supported communication strategies during semi-structured interviews (Harmon, Hardy, \& Haley, 2018; Luck \& Rose, 2007).

Analysis. All interviews were transcribed orthographically by a research assistant and subsequently coded in Atlas.ti 8.1.3 using thematic analysis (Braun \& Clarke, 2006). An eclectic coding process combined structural, descriptive, emotion, and magnitude coding strategies (Saldaña, 2013). All authors discussed and agreed upon the analytic approach prior to coding, which followed the same five-step iterative process described previously (Harmon, Jacks, Haley, \& Bailliard, 2019). First, the first author and a graduate student research assistant read through all transcripts. Next, the first author drafted an initial codebook based on his clinical experience, knowledge of the literature, and the aims of the study. The first author and research assistant then used the codebook to independently code the interview transcripts and worked collaboratively to refine the coded categories and definitions. This process involved multiple iterations of discussing the codebook codes and definitions, returning to the data to code independently, then discussing again. During this process, the author and research assistant identified several codes that they agreed to either delete or combine and others that they agreed to expande with subcodes. For example, the initial communication partner behavior code was subcoded to include the different types of behaviors mentioned (eye contact, phone use, vocal tone, body posture). Once the author and research assistant agreed that the codebook adequately represented the data, transcripts were recoded using the refined codebook. This resulted in ten discrepancies between the two coders, which were discussed and compared to codebook definitions to establish 
consensus about which of the listed codes was most applicable. After coding was complete, the first author, fourth author, and research assistant collaboratively organized codes into themes, subthemes, and categories. The final organization of themes and subthemes are presented in Table 3.

\section{Results}

Analysis of interview data revealed two themes relating to the experimental conditions and interview questions: first, "PWA react negatively to unresponsive partners," second, "unresponsive partners affect the communication experience." Subthemes were nested within each theme with some subthemes being broken down into categories for further description. In the following, we discuss each theme with its related subthemes and categories.

Theme I: PWA react negatively to unresponsive partners. Compared to control participants, comments from PWA emphasized unresponsive partner behaviors and reflected negative judgments and emotional reactions in response to these behaviors. PWA not only commented more frequently about unresponsive behaviors, negative judgments, and negative emotions, but their comments also reflected stronger overall reactions. For example, even though participants generally commented on feeling more "relaxed" with a responsive partner and "nervous" with an unresponsive partner, only PWA described becoming angry, frustrated, and "want[ing] someone else to come in here." When discussing their reactions, participants often contrasted the two story retell conditions. In doing so PWA were more likely to emphasize the negative experience of the unresponsive partner (e.g., "more stressed," "not as comfortable") whereas control participants were more likely to emphasize the positive experience of the responsive partner (e.g., "more engaging," "more at ease"). 
Five subthemes were identified that related to the reactions of participants to unresponsive partners. Subthemes A and B address the communication partner behaviors that participants noticed and the subsequent judgments they made about their communication partners. Subthemes C and D address participants' emotional reactions.

Subtheme I.A: PWA emphasized unresponsive behaviors and negative judgments.

When identifying behaviors and implying judgments about communication partners, PWA most frequently referred to their unresponsive partner. PWA frequently noticed the behaviors of their unresponsive partner and judged the partner as disinterested. They also described feeling uncomfortable because of these behaviors. While participants with moderate or mild aphasia identified similar specific behaviors, those behaviors were mentioned by all but four participants with moderate aphasia (A10, A12, A15, A21) compared to all but one with mild aphasia (A03). The specific unresponsive behaviors that participants identified were (1) eye contact, (2) phone use, (3) body posture, and (4) vocal tone.

"I can't see the eyes." Poor eye contact was the most frequently identified unresponsive behavior. Although participants from all groups noticed this behavior, it was most emphasized by participants with aphasia. Some mentioned that the unresponsive partner looked down and looked around the room; others simply stated, "she did not look at me." Two participants with moderate aphasia expressed frustration with their unresponsive partner commenting, "the eyes please. I can't see the eyes" (A20) and, "bring [the eyes] up" (A23).

“Looking at her phone.” Descriptions of the unresponsive partner's interaction with a mobile phone included that she "looked at her phone," "got on her phone," and "played with her phone.” Although participants from all groups mentioned similar interactions, participants with mild aphasia emphasized this behavior more than others and were particularly negative in their 
reaction to it. For example, after mentioning the phone, A02 exclaimed, "that drives me nuts... she was just sitting there with her cell phone and I didn't like that!”

Poor "body language." Three participants with moderate aphasia indicated that they noticed the closed body posture of the unresponsive partner. A06 mentioned it verbally and A13 and A22 demonstrated it by sitting back in their chair and folding their arms. In addition, four participants commented that the unresponsive partner seemed restless. They noticed that she "shifted in her seat," "fixed her clothes," and "started like picking at her arm."

Her introduction was "very sing-song." The patronizing voice used by the unresponsive communication partner during her introduction was described as "sing-song," "robotic," "loud," and "forceful." While people with and without aphasia mentioned this behavior, it was cast more negatively by PWA. As A01 complained, “don't come in the room and talk like she did. It was very sing-song, very slowly."

“She just wasn't listening. ” In general, PWA described the unresponsive communication partner as "the girl who did not pay attention," "wasn't listening," "seemed disinterested," and "was not really into it." These judgments were most often discussed in connection with unresponsive behaviors such as poor eye contact and phone use. Several participants also contrasted the two partners. For example, A16 said, "the [unresponsive partner]... seemed... disinterested; the [responsive] one seemed more interested."

She was "uptight." Five participants commented on whether or not the communication partner seemed comfortable listening to their story. The unresponsive partner was described as “introvert[ed]," "nervous," "uptight," and "not at ease in my presence." These descriptions were given by both participants with aphasia and control participants, but comments from PWA suggested that their judgments about the partner's discomfort had a direct impact on their 
reaction. For example, A18 reasoned “when someone's not paying attention, you can't help but not feel comfortable." Participants with aphasia, therefore, interpreted unresponsive behaviors as indicating discomfort, which, in turn, affected their own comfort during the communicative exchange.

In sum, participants with aphasia were especially bothered by unresponsive partner behaviors and interpreted these behaviors as reflecting the partner's level of interest and comfort. Often, their recognition of these behaviors and subsequent judgments seemed to trigger emotional reactions.

\section{Subtheme I.B: Control participants emphasized responsive behaviors and positive}

judgments. Although participants with no aphasia noticed unresponsive behaviors, most of their comments emphasized responsive behaviors exhibited by their communication partner and their subsequent positive judgments. On the other hand, participants with aphasia seldom emphasized responsive behaviors and rarely described positive judgments of their communication partners.

"She was smiling." Participants from all groups noticed and commented that the responsive communication partner smiled, laughed, and gave "encouraging gestures" and "verbal cues” (i.e., 'uh-huh,' 'yeah'), but these behaviors were primarily emphasized by control participants. In addition to mentioning these behaviors more frequently than participants with aphasia, control participants explained how smiles, "verbal cues," and "laughing at the little jokey bits" helped them to know that the communication partner "was following along."

"She was pleasant" and "encouraging." Participants described the responsive partner as “friendly," "nice," "pleasant," "kind," "encouraging," and "approachable." When explaining their judgments about the communication partner, control participants often contrasted the two partners but did so in a way that highlighted their positive judgments of the responsive partner. 
For example, C08 explained that "the [responsive partner] seemed to be easier-more approachable. The [unresponsive partner] seemed to be a little less approachable." $\mathrm{C} 12$ said that "the [unresponsive partner] was very quiet... the [responsive partner] was more engaging." Participants with aphasia also described the responsive partner as "pleasant" and "nice" but most often emphasized their negative judgment of the unresponsive partner describing her as "stiff," “stern," and "angry."

Overall, comments from control participants highlighted responsive behaviors and positive judgments associated with the responsive communication partner. They rarely comment on behaviors and judgments of unresponsive partners and, when they did, characterized them less negatively than the participants with aphasia.

\section{Subtheme I.C: PWA experienced negative emotional reactions to unresponsive}

partners. When commenting about how they felt retelling a story to an unresponsive partner, PWA emphasized negative emotional reactions. Although these reactions were emphasized by all participants with aphasia, those with mild aphasia generally reported more frequent and intense emotional reactions. This increased intensity was manifest through descriptions that (a) indicated stronger emotions (e.g., anger and stress) and (b) more clearly distinguished between emotions in the responsive and nonresponsive partner conditions.

"I was nervous." PWA described themselves as feeling uncomfortable when talking to the unresponsive partner. Discomfort was expressed through comments about nervousness, wanting someone else to talk to, and not being able to "read" the unresponsive partner. When comparing their interactions with unresponsive compared to responsive partners, participants described feeling "not as comfortable" and less "at ease." Although two participants with 
moderate aphasia (A13, A21) described feeling nervous with both communication partners, they expressed feeling more comfortable with the responsive partner.

It was "frustrating” and "stressful." PWA experienced feelings of frustration and stress when retelling a story to an unresponsive partner. Feelings of frustration were expressed by four participants with moderate aphasia and were often connected with the unresponsive partner's poor eye contact. Three participants with mild aphasia described telling a story to an unresponsive partner as "really stressful." They often described feeling "more stressed" when talking to the unresponsive partner than when talking to the responsive partner. Throughout her interview, A17 repeatedly mentioned the stress she felt when talking to the unresponsive partner. "I don't want to talk to you." When retelling a story to an unresponsive partner, some PWA became angry, irritated, or lost their desire to do well and keep trying. Two participants with mild aphasia expressed sentiments of anger in reaction to the unresponsive partner. For example, when asked how participants felt talking to the unresponsive partner, A02 responded, "pretty messed up. Mad!" and A09 reported that she was "not happy." Two PWA (1 moderate, 1 mild) mentioned the communication partner's influence on their motivation (i.e., their desire to do well and keep trying). For example, A22 expressed wanting to just quit when telling a story to the unresponsive partner. Such feelings of irritation and decreased motivation are likely to engender social withdrawal.

"I don't think it bothered me, I just noticed it." Seven PWA (3 moderate, 4 mild) described noticing the unresponsive behaviors but having mixed or uncertain emotional reactions. For example, when talking about the unresponsive partner's lack of interest, A04 said, “that was fine except I'm here telling a story and she's like doing stuff.” Referring to the unresponsive partner's poor eye contact, A19 said, "I don't think it bothered me, ... I just noticed 
it." Two participants with moderate aphasia (A20 and A15) were confused about the unresponsive behaviors. A15 wondered if her lack of support was because he was saying the wrong thing or because she just wasn't "very excited about [listening to the story]." Even for PWA who reported minimal emotional reactions, the unresponsive partner was distracting and may have diverted their attention from the story retell task. In summary, PWA commonly reported negative emotional reactions to unresponsive communication partners, which seemed even more poignant for participants with mild aphasia.

\section{Subtheme I.D: Control participants experienced few emotional reactions to}

unresponsive partners. As noted previously, the majority of comments about emotional reactions were made by PWA. Although control participants rarely mentioned their emotional response, their comments most often described positive emotional reactions to the responsive partner (e.g., feeling at ease, enjoying telling the story) rather than negative reactions to the unresponsive partner. For example, control participants described retelling a story to a responsive partner as "pleasant," and "enjoyable." C04 described feeling "comfortable," and C12 felt "at ease."

Theme II: Unresponsive partners affect the communication experience. Relative to the responsive partner condition, participants generally reported that the unresponsive partner negatively interfered with the communication experience. Overall, however, participants were split on how they self-assessed their story retell in this condition. Some participantsparticularly those with mild aphasia —also discussed using intentional strategies when retelling a story in the unresponsive partner condition.

Three subthemes were identified relating to how participants described the effect of an unresponsive partner on their communication experience. Subtheme A relates to behavioral 
reactions. Subtheme B describes how PWA self-assessed their performance in each condition. Subtheme $\mathrm{C}$ describes the intentional strategies that participants reported using during the unresponsive partner condition.

Subtheme II.A: “I don't know if that changed anything that I did" - mixed behavioral reactions to unresponsive partners. Behavioral reactions to the communication partners varied among participants. Most described specific behavioral reactions; some had mixed feelings about how they reacted behaviorally; others indicated that they had no reaction.

Ten PWA (6 moderate, 4 mild) and five controls indicated some behavioral reaction to the communication partner. In general, they described talking to the unresponsive partner as "harder" and the responsive partner as "easier" and mentioned specific ways that the partners influenced their communicative behavior. Several participants suggested that telling the story to an unresponsive partner caused them to talk less and leave information out. Others described rushing through the story or having to "stop and restart again." Two participants with mild aphasia (A04, A16) and one control participant (C11) suggested that the unresponsive partner had a distracting influence on their story retell. For example, A16 stated that his partner's behaviors caused him to be "almost taken off task." Two separate participants reported reacting by closing their eyes while retelling the story. A10 said that she closed her eyes in both conditions, but A03 reported only closing her eyes in the unresponsive partner condition. Approximately one-quarter of participants (2 moderate, 4 mild, 3 control) had mixed feelings regarding their behavioral reaction to the communication partner. When referring to the unresponsive partner's impact on their story retell, two participants with mild aphasia (A02, A08) began to indicate that they had performed worse but before making a conclusive statement, self-interrupted and resolved that they had actually performed "about the same," or "close to 
normal." This may have been the result of uncertainty about their behavioral reactions or hesitancy to expose the unresponsive partner. The other participants noticed the unresponsive behaviors, but didn't feel that it changed how they retold the story.

\section{Subtheme II.B: PWA self-assessed their performance differently depending on the}

story retell condition. How participants with aphasia self-assessed their story retell differed depending on the condition. They provided a positive self-assessment of their performance when talking to a responsive partner and a mixed assessment when talking to an unresponsive partner.

PWA thought they did "very good" when telling a story to a responsive partner.

Although they admitted that they did not retell the story perfectly, PWA (regardless of severity) felt like they did "very good" when talking to a responsive communication partner. Often, these comments were made relative to the other condition to indicate that participants thought they did "better" or "best." Self-assessments, therefore, seemed to be relative to other recent communication experiences.

PWA gave a mixed self-assessment of a story told to an unresponsive partner. Participants were split on their self-assessment for the story retold to an unresponsive communication partner. Five PWA ( 3 moderate, 2 mild) assessed their performance negatively. They described their performance as "bad," "horrible," "hardest," and "worst," explaining that they "left a lot of things out" and "didn’t [say] as much." Six PWA (4 moderate, 2 mild) provided a positive self-assessment. They described their performance in the unresponsive partner condition as "good," "easy," and "fine." Three PWA (1 moderate, 2 mild) gave a mixed assessment of their performance when talking to an unresponsive partner: The two with mild aphasia were "not sure" how well they did; The participant with moderate aphasia said he felt like he did well but "couldn't [say the] words." 
Overall, when reflecting and commenting on how well they retold stories in each condition, PWA were pleased with their performance in the responsive partner condition, but varied in how they perceived their performance in the unresponsive partner condition. The mixed self-assessments in the unresponsive partner condition suggests that people with aphasia are uncertain about their communication with unresponsive partners and may vary in their reactions.

\section{Subtheme II.C: People with mild aphasia used intentional strategies to cope with}

unresponsive partners. Participants identified a number of strategies that helped them perform the story retell task in the unresponsive partner condition. Comments about strategies were made primarily by participants with mild aphasia. All participants with mild aphasia except three mentioned at least one intentional strategy whereas strategies were only mentioned by one participant with moderate aphasia and one control participant. The strategies included (1) focus, (2) getting it over with, (3) big picture, and (4) revision.

Focus. The most common strategy that participants mentioned was focusing on the story. Participants with mild aphasia described forcing themselves to focus on the story by filtering out distractions. A03 described closing her eyes so she could visualize the pictures. Three participants (A17, A18, and A19) explicitly commented on attending to the story more than the unresponsive partner behaviors. No participants with moderate aphasia mentioned this strategy.

Getting it over with. Three participants (1 moderate, 2 mild) described the strategy of moving forward in order to get through the story quickly. The two with mild aphasia (A01, A04) described using this strategy to avoid forgetting details. The participant with moderate aphasia (A06) explained that she used this strategy when talking to the unresponsive partner so that she could "get it done" quickly. 
Big Picture. Two participants (1 mild, 1 control) described a strategy that involved focusing on the main points or basic structure of the story without getting caught up in the small details. They explained that this helped ensure that they included "the point of the story" without having to "remember every single detail."

Revision. One participant with mild aphasia (A11) discussed going back to correct mistakes or revisit details she forgot.

\section{Discussion}

The purpose of the second study was to explore how PWA subjectively respond to different levels of communication partner responsiveness and compare their response to neurotypical adults. Qualitative findings showed that PWA were particularly attuned to unresponsive partner behaviors and reported strong negative emotional reactions when retelling a story to an unresponsive partner. Communication partner responsiveness also affected how PWA perceived the overall communication experience.

Study 2 showed that PWA are more attuned to unresponsive communication partner behaviors than their neurotypical peers, which leads to more intense negative emotional reactions. Because a bias towards negative information can indicate risk for depression and anxiety (Watters \& Williams, 2011; Williams et al., 2009), this finding highlights the need to further understand relationships between aphasia and mood disorders. The emphasis that PWA put on unresponsive partner behaviors and negative emotions may indicate signs of depression or anxiety, or at least make them vulnerable to socially challenging communication situations.

Among participants with moderate and mild aphasia, unresponsiveness from a communication partner was more distressing for the mild group. This distinction was probably the result of differences in the extent to which these groups recognized and processed the 
unresponsive partner behaviors. Participants with moderate aphasia mentioned unresponsive behaviors less than those with mild aphasia. In fact, of the five PWA who did not mention unresponsive behaviors, only one was from the mild aphasia group. Perhaps participants with moderate aphasia were either more habituated to unresponsive partner feedback or more focused on the communication task, which caused them to attend less to unresponsive behaviors. Even though their language functioning is better than those with moderate aphasia, people with mild aphasia continue to experience negative psychosocial consequences (Parr, 2001).

In the present study, participants who attended to unresponsive communication partner behaviors were more likely to become emotionally distressed, which, in turn, affected how they self-evaluated their performance. In fact, only one of the seven participants who provided positive self-evaluations of their story retell performance in the unresponsive partner condition reported any emotional reaction. Several participants prevented those reactions by conscientiously ignoring unresponsive partner behaviors. Although focusing on the story retell task seemed an effective intentional coping strategy in the present study, its use in everyday communication situations may be more problematic. While averting strong emotional reactions by concentrating on transmitting information, PWA might simultaneously sacrifice emotional connection with their communication partner.

Explicit training could prepare PWA for socially challenging communication situations by teaching strategies or practicing in simulated environments. Training on relaxation techniques, for example, might help PWA better cope with unresponsive partners without risking social connection. Such training might include stress monitoring, tension control (DuBay et al., 2011), or mindfulness meditation (Dickinson et al., 2017; Marshall et al., 2018). Training in simulated environments that pose greater social challenge than a clinical setting might also be 
useful. For example, virtual reality interview and public speaking environments have been created and tested with people who stutter and might also be applicable to aphasia therapy (Brundage, Graap, Gibbons, Ferrer, \& Brooks, 2006; Brundage \& Hancock, 2015). Future research is needed to learn what strategies and simulations would best apply to aphasia intervention.

Because partner responsiveness affects how PWA think about and evaluate their success following communicative interactions, it has the potential to promote or restrict future social participation. Unsupportive backchannel responses from the communication partner led PWA to express less certainty about their communicative success, thus decreasing self-efficacy (Bandura, 1997). This finding implies that even if unresponsive partner feedback does not directly hinder communicative performance, it might make PWA feel uncertain about their communication, which could be increasingly detrimental over time. Previous studies suggest that it is often the perception of PWA about the situation rather than their actual performance that leads them to avoid or withdraw from participation (Dalemans et al., 2010; Le Dorze et al., 2014). To increase social participation, therefore, clinicians should not only assess spoken language but also perceptions about communication. This could be done using self-efficacy ratings (Bandura, 2006) or goal attainment scaling (Malec, Smigielski, \& DePompolo, 1991).

Limitations. Unlike previous studies that have explored how PWA respond to everyday social challenge while participating in life roles (Baylor et al., 2011) or in the workplace (Garcia et al., 2000), we interviewed participants immediately following an emotionally demanding communication situation that was manipulated experimentally. While this provided an opportunity for participants to reflect on the same recent experience, there were also limitations posed by this approach. 
First, because the responsive and unresponsive partner conditions relied on experimental manipulations, they lacked the ecological validity of a genuine experience from the participants' everyday life. This was evident in comments from some participants who wondered if the lack of support from an unresponsive partner was intentional. Findings, therefore, should be generalized with caution. Genuine experiences from participants' everyday lives, however, may have led to similar but stronger reactions. This was highlighted by A02 who commented that she would have reacted even more strongly if she hadn't been participating in an experiment. The gender and age of the students who acted as communication partners may have also had an effect on participant reactions. Using older adults as communication partners would more closely resemble everyday communication for these participants.

Second, the first author filling the role of investigator and interviewer may have biased some of the responses given by participants. One example of how this was manifest was through some participants being hesitant to speak negatively about the unresponsive partner. Because the first author was in a position of power with the students who were acting as communication partners, participants may have feared that they were putting the "unresponsive" student at risk by openly sharing their observations.

\section{Conclusions}

People with aphasia frequently interact with unresponsive communication partners (Le Dorze et al., 2014; Parr, 2001; Skelly, 1975). The purpose of the present work was to investigate how partner responsiveness influenced quantitative measures of psychological stress and story retell performance as well as subjective reactions. Combined quantitative and qualitative findings showed that partner responsiveness had variable effects on story retell performance, but strong effects on emotional response. This was shown by significantly higher psychological stress 
ratings in study 1 and frequent reporting of strong negative emotional reactions in study 2 , which were more poignant for PWA than controls. In addition to stimulating intense emotional reactions from participants with aphasia, unresponsive communication partners led to decreased self-efficacy and increased focus on information transmission. Emotions have an important role in promoting social participation in aphasia that clinicians should recognize and draw upon in assessment and treatment. When appropriate, treatment techniques could be used to help PWA regulate heightened emotional responses. Future research should uncover how to best integrate emotion and emotion regulation into assessment and treatment in aphasia.

Acknowledgments: This work was supported by a Dissertation Completion Fellowship Award from the University of North Carolina Graduate School. Special thanks to Daniel Picetti, Marissa Rock, Laura Blizard, Madison Goers, Jenna Hall, Emmie Costen, Tayler Simonds, Morgan Billinger, and Matthew Suderman for their help with data collection and analysis. We also wish to thank the Triangle Aphasia Project, unlimited for their help with recruitment and Dr. Bonnie Brinton for her feedback on an earlier version of this manuscript. 


\section{References}

Bandura, A. (1997). Self-Efficacy: The Exercise of Control. New York: W. H. Freeman and Company. Retrieved from https://books.google.com/books/about/Self_Efficacy.html?id=eJPN9g_o-EC\&pgis=1

Bandura, A. (2006). Guide for constructing self-efficacy scales. In Self-efficacy beliefs of adolescents (pp. 307-337).

Baylor, C., Burns, M., Eadie, T., Britton, D., \& Yorkston, K. (2011). A qualitative study of interference with communicative participation across communication disorders in adults. American Journal of Speech-Langauge Pathology, 20(November), 269-287. http://doi.org/10.1044/1058-0360(2011/10-0084)intervention

Braun, V., \& Clarke, V. (2006). Using thematic analysis in psychology. Qualitative Research in Psychology, 3(2), 77-101. http://doi.org/10.1191/1478088706qp063oa

Britten, N. (1995). Qualitative research: Qualitative interviews in medical research. BMJ (Clinical Research Ed.), 311(6999), 251-253. http://doi.org/10.1136/bmj.311.6999.251

Brundage, S. B., Graap, K., Gibbons, K. F., Ferrer, M., \& Brooks, J. (2006). Frequency of stuttering during challenging and supportive virtual reality job interviews. Journal of Fluency Disorders, 31(4), 325-339. http://doi.org/10.1016/j.jfludis.2006.08.003

Brundage, S. B., \& Hancock, A. B. (2015). Real enough: Using virtual public speaking environments to evoke feelings and behaviors targeted in stuttering assessment and treatment. Journal of Speech, Language, and Hearing Research, 24(May), 139-149. http://doi.org/10.1044/2014_AJSLP-14-0087

Buchanan, T. W., Laures-Gore, J. S., \& Duff, M. C. (2014). Acute stress reduces speech fluency. Biological Psychology, 97(1), 60-66. http://doi.org/10.1016/j.biopsycho.2014.02.005

Cahana-Amitay, D., Oveis, A. C., Sayers, J. T., Pineles, S. L., Spiro, A., \& Albert, M. L. (2015). Biomarkers of "Linguistic Anxiety" in aphasia: A proof-of-concept case study. Clinical Linguistics \& Phonetics, 29(5), 401-413. http://doi.org/10.3109/02699206.2015.1014572

Chapey, R., Duchan, J. F., Elman, J., Garcia, L. J., Kagan, A., Lyon, J. G., \& Simmons-Mackie, N. (2000). Life participation approach to aphasia: A statement of values for the future. The ASHA Leader, 1-15.

Croteau, C., \& Le Dorze, G. (2001). Spouses' perceptions of persons with aphasia. Aphasiology, 15(April 2001), 37-41. http://doi.org/10.1080/02687040143000221

Dalemans, R. J. P., de Witte, L., Wade, D., \& van den Heuvel, W. (2010). Social participation through the eyes of people with aphasia. International Journal of Language \& Communication Disorders, 45(5), 537-550. http://doi.org/10.3109/13682820903223633

Davidson, B., Howe, T., Worrall, L., Hickson, L., \& Togher, L. (2008). Social participation for 
older people with aphasia: The impact of communication disability on friendships. Topics in Stroke Rehabilitation, 15(4), 325-340. http://doi.org/10.1310/tsr1504-325

Dickinson, J., Friary, P., \& McCann, C. M. (2017). The influence of mindfulness meditation on communication and anxiety: A case study of a person with aphasia. Aphasiology, 31(9), 1044-1058. http://doi.org/10.1080/02687038.2016.1234582

Doyle, P. J., McNeil, M. R., Spencer, K. A., Goda, A. J., Cottrell, K., \& Lustig, A. P. (1998). The effects of concurrent picture presentations on retelling of orally presented stories by adults with aphasia. Aphasiology, 12(7-8), 561-574. http://doi.org/10.1080/02687039808249558

DuBay, M. F., Laures-Gore, J. S., Matheny, K., \& Romski, M. A. (2011). Coping resources in individuals with aphasia. Aphasiology, 25(9), 1016-1029. http://doi.org/10.1080/02687038.2011.570933

Garcia, L. J., Barrette, J., \& Laroche, C. (2000). Perceptions of the obstacles to work reintegration for persons with aphasia. Aphasiology, 14(3), 269-290. http://doi.org/10.1080/026870300401478

Harmon, T. G., Hardy, L., \& Haley, K. L. (2018). Proactive social validation of methods and procedures used for training speech production in aphasia. Aphasiology, 32(8), 922-943. http://doi.org/10.1080/02687038.2017.1385051

Harmon, T. G., Jacks, A., Haley, K. L., \& Bailliard, A. (2019). Dual-task effects on story retell for participants with moderate, mild, or no aphasia: Quantitative and qualitative findings. Journal of Speech, Language, and Hearing Research, 62(6), 1890-1905. https://doi.org/10.1044/2019_JSLHR-L-18-0399

Harmon, T. G., Jacks, A., Haley, K. L., \& Faldowski, R. A. (2016). Listener perceptions of simulated fluent speech in nonfluent aphasia. Aphasiology, 30(8), 922-942. http://doi.org/10.1080/02687038.2015.1077925

Hilmert, C. J., Christenfeld, N., \& Kulik, J. a. (2002). Audience status moderates the effects of social support and self-efficacy on cardiovascular reactivity during public speaking. Annals of Behavioral Medicine : A Publication of the Society of Behavioral Medicine, 24, 122-131. http://doi.org/10.1207/S15324796ABM2402_09

Jones, W. J., Williams, L. S., \& Meschia, J. F. (2001). Validating the Questionnaire for Verifying Stroke-Free Status (QVSFS) by neurological history and examination. Stroke, 32(10), 2232-2236. http://doi.org/10.1161/hs1001.096191

Kagan, A. (1998). Supported conversation for adults with aphasia : methods and resources for training conversation partners. Aphasiology, 12(9), 816-830.

Kagan, A., Black, S., Duchan, J., Simmons-Mackie, N., \& Square, P. (2001). Training Volunteers as Conversation Partners Using "Supported Conversation for Adults With Aphasia" (SCA): A Controlled Trial. Journal of Speech, Language, and Hearing Research, 
44(June), 624-638.

Kertesz, A. (2006). Western Aphasia Battery-Revised (WAB-R). San Antonio, TX: Pearson. Retrieved from http://www.asha.org/SLP/assessment/Western-Aphasia-Battery-Revised(WAB-R).htm

Laures-Gore, J. S., \& Buchanan, T. W. (2015). Aphasia and the neuropsychobiology of stress. Journal of Clinical and Experimental Neuropsychology, 37(7), 688-700. http://doi.org/10.1080/13803395.2015.1042839

Laures-Gore, J. S., DuBay, M. F., Duff, M. C., \& Buchanan, T. W. (2010). Identifying behavioral measures of stress in individuals with aphasia. Journal of Speech, Language, and Hearing Research, 53(5), 1394-1400. http://doi.org/10.1044/1092-4388(2010/09-0236)

Laures-Gore, J. S., Heim, C. M., \& Hsu, Y.-S. (2007). Assessing Cortisol Reactivity to a Linguistic Task as a Marker of Stress in Individuals With Left-Hemisphere Stroke and Aphasia. Journal of Speech Language and Hearing Research, 50(2), 493. http://doi.org/10.1044/1092-4388(2007/034)

Le Dorze, G., Salois-Bellerose, É., Alepins, M., Croteau, C., \& Hallé, M.-C. (2014). A description of the personal and environmental determinants of participation several years post-stroke according to the views of people who have aphasia. Aphasiology, 28(4), 421439. http://doi.org/10.1080/02687038.2013.869305

Lenth, R. (2017). emmeans: Estimated Marginal Means, aka Least-Squares Means.

Lepore, S. J., Allen, K. a, \& Evans, G. W. (1993). Social support lowers cardiovascular reactivity to an acute stressor. Psychosomatic Medicine, 55, 518-524.

http://doi.org/10.1097/00006842-199311000-00007

Luck, A. M., \& Rose, M. L. (2007). Interviewing people with aphasia: Insights into method adjustments from a pilot study. Aphasiology, 21(2), 208-224. http://doi.org/10.1080/02687030601065470

Malec, J. F., Smigielski, J. S., \& DePompolo, R. W. (1991). Goal attainment scaling and outcome measurement in postacute brain injury rehabilitation. Archives of Physical Medicine \& Rehabilitation, 72(February), 138-143.

Marshall, R. S., Laures-Gore, J., \& Love, K. (2018). Brief mindfulness meditation group training in aphasia: Exploring attention, language and psychophysiological outcomes. International Journal of Language and Communication Disorders, 53(1), 40-54.

http://doi.org/10.1111/1460-6984.12325

McCroskey, J. C., Beatty, M. J., Kearney, P., \& Plax, T. G. (1985). The content validity of the PRCA-24 as a measure of communication apprehension across communication contexts. Communication Quarterly, 33(3), 165-173. http://doi.org/10.1080/01463378509369595

McCroskey, J. C., \& Richmond, V. P. (1982). Communication apprehension and shyness: 
Conceptual and operational distinctions. Communication Studies, 33(3), 458-468.

http://doi.org/10.1080/10510978209388452

McNeil, M. R., Sung, J. E., Yang, D., Pratt, S. R., Fossett, T. R. D., Doyle, P. J., \& Pavelko, S. (2007). Comparing connected language elicitation procedures in persons with aphasia:

Concurrent validation of the Story Retell Procedure. Aphasiology, 21, 775-790. http://doi.org/10.1080/02687030701189980

Parr, S. (2001). Psychosocial aspects of aphasia: Whose perspectives? Folia Phoniatrica et Logopaedica, 53(5), 266-88. http://doi.org/52681

Parr, S. (2007). Living with severe aphasia: Tracking social exclusion. Aphasiology, 21(1), 98123. http://doi.org/10.1080/02687030600798337

Pinheiro, J., Bates, D., Debroy, S., Sarkar, D., \& Team, R. C. (2017). nlme: Linear and nonlinear mixed effects models. Retrieved from https://cran.r-project.org/package=nlme

R Core Team. (2017). R: A language and environment for statistical computing. Vienna, Austria: R Foundation for Statistical Computing. Retrieved from http://www.r-project.org/

Saldaña, J. (2013). The Coding Manual for Qualitative Researchers (2nd ed.). Los Angeles: SAGE Publications.

Simmons-Mackie, N., \& Kagan, A. (1999). Communication strategies used by "good" versus "poor" speaking partners of individuals with aphasia. Aphasiology, 13(9-11), 807-820. http://doi.org/10.1080/026870399401894

Skelly, M. (1975). Re-thinking stroke: Aphasic patients talk back. American Journal of Nursing, $75(7), 1140-1142$.

Thorsteinsson, E. B., \& James, J. E. (1999). A meta-analysis of the effects of experimental manipulations of social support during laboratory stress. Psychology and Health, 14, 869886.

Watters, A. J., \& Williams, L. M. (2011). Negative biases and risk for depression; Integrating self-report and emotion task markers. Depression and Anxiety, 28(8), 703-718. http://doi.org/10.1002/da.20854

Williams, L. M., Gatt, J. M., Schofield, P. R., Olivieri, G., Peduto, A., \& Gordon, E. (2009). "Negativity bias" in risk for depression and anxiety: Brain-body fear circuitry correlates, 5HTT-LPR and early life stress. NeuroImage, 47(3), 804-814. http://doi.org/10.1016/j.neuroimage.2009.05.009

Yerkes, R. M., \& Dodson, J. D. (1908). The relation of strength of stimulus to rapidity of habitformation. Journal of Comparative Neurology and Psychology, 18(5), 459-482. http://doi.org/10.1002/cne.920180503

Yesavage, J. A., \& Sheikh, J. I. (1986). Geriatric Depression Scale (GDS). Clinical 
Gerontologist, 5(1-2), 165-173. http://doi.org/10.1300/J018v05n01 
Table 1. Participant Information.

\begin{tabular}{|c|c|c|c|c|c|c|c|c|c|c|c|c|c|c|}
\hline \multirow[t]{2}{*}{ ID } & \multirow[t]{2}{*}{ Sex } & \multirow[t]{2}{*}{ Age } & \multirow[t]{2}{*}{ Education } & \multirow{2}{*}{$\begin{array}{l}\text { Marital } \\
\text { Status }\end{array}$} & \multirow{2}{*}{$\begin{array}{l}\text { Aphasia } \\
\text { Severity }\end{array}$} & \multirow{2}{*}{$\begin{array}{c}\text { TPO } \\
\text { (yy;mm) }\end{array}$} & \multirow[t]{2}{*}{ PRCA-24 } & \multirow[t]{2}{*}{ GDS } & \multicolumn{6}{|c|}{ WAB-R } \\
\hline & & & & & & & & & $A Q$ & Classification & Fluency & $\begin{array}{l}\text { Spont. } \\
\text { Speech }\end{array}$ & $\begin{array}{l}\text { Aud. } \\
\text { Comp. }\end{array}$ & Naming \\
\hline $\mathrm{A} 01$ & $\mathrm{~F}$ & 58 & 20 & Widowed & Mild & $14 ; 00$ & 61 & 1 & 87.0 & Anomic & 9 & 18 & 8.3 & 8.5 \\
\hline $\mathrm{A} 02$ & $\mathrm{~F}$ & 56 & 14 & Married & Mild & 4;05 & 59 & 4 & 90.7 & Anomic & 9 & 19 & 8.45 & 8.6 \\
\hline A03 & $\mathrm{F}$ & 81 & 15 & Married & Mild & $5 ; 07$ & 46 & 0 & 92.7 & Anomic & 9 & 19 & 9.15 & 9 \\
\hline A04 & M & 33 & 16 & Single & Mild & $5 ; 11$ & 34 & 5 & 87.6 & Anomic & 9 & 19 & 8.5 & 7.9 \\
\hline A06 & $\mathrm{F}$ & 48 & 17 & Married & Moderate & $18 ; 04$ & 93 & 2 & 77.8 & $\begin{array}{l}\text { Transcortical } \\
\text { Motor }\end{array}$ & 4 & 13 & 7.4 & 6.9 \\
\hline A08 & M & 56 & 16 & Married & Mild & $2 ; 01$ & 94 & 5 & 100.0 & NABW & 10 & 20 & 10 & 8.5 \\
\hline A09 & $\mathrm{F}$ & 59 & 16 & Married & Mild & $1 ; 10$ & 71 & 1 & 89.9 & Anomic & 9 & 19 & 7.65 & 2.8 \\
\hline A10 & $\mathrm{F}$ & 72 & 12 & Married & Moderate & $8 ; 00$ & 60 & 0 & 72.2 & Broca & 4 & 14 & 9.9 & 10 \\
\hline A11 & $\mathrm{F}$ & 65 & 15 & Married & Mild & $7 ; 07$ & 44 & 2 & 84.3 & Anomic & 9 & 19 & 8.95 & 9.7 \\
\hline A12 & $\mathrm{F}$ & 61 & 16 & Divorced & Moderate & $11 ; 03$ & 48 & 1 & 74.1 & Anomic & 6 & 15 & 7.65 & 6.6 \\
\hline A13 & $\mathrm{F}$ & 61 & 13 & Married & Moderate & $5 ; 04$ & 69 & 5 & 67.5 & Broca & 4 & 12 & 8.55 & 7.9 \\
\hline A14 & $M$ & 61 & 20 & Married & Moderate & $5 ; 08$ & 56 & 3 & 67.0 & Wernicke's & 8 & 17 & 5.6 & 7 \\
\hline A15* & $M$ & 70 & 16 & Married & Moderate & $1 ; 11$ & 53 & 3 & 76.9 & Conduction & 9 & 17 & 7.95 & 6.6 \\
\hline A16 & $M$ & 60 & 22 & Married & Mild & $4 ; 08$ & 46 & 3 & 95.4 & NABW & 9 & 19 & 10 & 8 \\
\hline A17 & $\mathrm{F}$ & 72 & 18 & Divorced & Mild & $9 ; 09$ & 70 & 2 & 82.8 & Anomic & 6 & 15 & 9.1 & 6.7 \\
\hline A18 & $\mathrm{F}$ & 71 & 16 & Married & Mild & $18 ; 01$ & 66 & 1 & 94.0 & NABW & 10 & 19 & 10 & 9.7 \\
\hline A19 & M & 72 & 18 & Married & Mild & $8 ; 02$ & 73 & 4 & 97.4 & NABW & 9 & 19 & 10 & 9 \\
\hline A20 & M & 60 & 18 & Married & Moderate & $8 ; 07$ & 61 & 4 & 75.0 & Anomic & 5 & 14 & 8.7 & 8 \\
\hline A21 & $\mathrm{F}$ & 32 & 13 & Single & Moderate & $11 ; 11$ & 43 & 0 & 63.7 & Conduction & 6 & 13 & 7.35 & 10 \\
\hline A22 & $\mathrm{F}$ & 56 & 16 & Married & Moderate & $12 ; 09$ & 80 & 2 & 52.1 & Broca & 4 & 11 & 7.65 & 7.7 \\
\hline A23 & $M$ & 64 & 18 & Married & Moderate & $3 ; 02$ & 57 & 1 & 72.7 & Broca & 4 & 12 & 9.35 & 5.1 \\
\hline A24 & $M$ & 48 & 19 & Married & Moderate & $1 ; 07$ & 36 & 3 & 68.2 & Broca & 4 & 13 & 8.5 & 4.1 \\
\hline C01 & $\mathrm{F}$ & 71 & 16 & Single & - & - & 60 & - & - & - & - & - & - & - \\
\hline $\mathrm{CO} 2^{*}$ & M & 70 & 21 & Married & - & - & 33 & - & - & - & - & - & - & - \\
\hline $\mathrm{CO3}$ & $\mathrm{F}$ & 50 & 16 & Married & - & - & 45 & - & - & - & - & - & - & - \\
\hline $\mathrm{CO4}$ & $\mathrm{F}$ & 55 & 13 & Married & - & - & 44 & - & - & - & - & - & - & - \\
\hline $\mathrm{CO5}$ & $\mathrm{F}$ & 33 & 18 & Married & - & - & 43 & - & - & - & - & - & - & - \\
\hline C06 & $\mathrm{F}$ & 81 & 18 & Single & - & - & 48 & - & - & - & - & - & - & - \\
\hline $\mathrm{CO}$ & $\mathrm{F}$ & 34 & 16 & Married & - & - & 74 & - & - & - & - & - & - & - \\
\hline $\mathrm{CO8}$ & $\mathrm{F}$ & 60 & 12 & Single & - & - & 63 & - & - & - & - & - & - & - \\
\hline CO9 & $M$ & 64 & 18 & Married & - & - & 26 & - & - & - & - & - & - & - \\
\hline $\mathrm{C} 10$ & $M$ & 66 & 18 & Married & - & - & 39 & - & - & - & - & - & - & - \\
\hline C11 & M & 48 & 14 & Married & - & - & 84 & - & - & - & - & - & - & - \\
\hline $\mathrm{C} 12$ & M & 61 & 16 & Married & - & - & 66 & - & - & - & - & - & - & - \\
\hline
\end{tabular}

Note. Age and Education are reported in years. TPO = time post-onset; PRCA-24 = Personal Report of Communication Apprehension (McCroskey et al., 1985); GDS = Geriatric Depression Scale; WAB-R = Western Aphasia Battery-Revised (Kertesz, 2006); AQ = Aphasia Quotient; Spont. Speech $=$ Spontaneous Speech; Aud. Comp. $=$ Auditory Comprehension. * Included in study 2 but not study 1 . 
Table 2. Descriptive Data for Story Retell Performance Among Participant Groups Within Responsive and Unresponsive Partner Conditions.

\begin{tabular}{|c|c|c|c|c|c|c|c|}
\hline & & \multicolumn{2}{|c|}{ Moderate Aphasia } & \multicolumn{2}{|c|}{ Mild Aphasia } & \multicolumn{2}{|c|}{ Control } \\
\hline & & $\mathrm{RP}$ & UP & $\mathrm{RP}$ & UP & $\mathrm{RP}$ & UP \\
\hline \multirow[t]{4}{*}{ Productivity } & $M$ & 43.50 & 47.90 & 108.82 & 90.18 & 195.00 & 172.17 \\
\hline & $S D$ & 32.88 & 36.91 & 44.97 & 35.84 & 80.66 & 42.79 \\
\hline & Median & 36.00 & 39.00 & 106.00 & 89.00 & 169.00 & 175.50 \\
\hline & Range & $13-122$ & $9-121$ & $38-207$ & $37-159$ & $116-426$ & $103-246$ \\
\hline \multirow[t]{4}{*}{ Efficiency } & $M$ & 36.84 & 37.86 & 62.37 & 62.81 & 87.36 & 88.73 \\
\hline & $S D$ & 18.62 & 16.54 & 19.98 & 17.19 & 8.59 & 6.65 \\
\hline & Median & 33.28 & 39.95 & 61.63 & 56.22 & 89.05 & 90.78 \\
\hline & Range & $17.92-72.22$ & $11.80-63.25$ & $22.75-95.74$ & $34.26-86.41$ & $70.04-97.48$ & 75.61-97.03 \\
\hline \multirow[t]{4}{*}{ Rate } & $M$ & 47.92 & 44.43 & 102.16 & 98.23 & 158.52 & 143.60 \\
\hline & $S D$ & 19.51 & 19.85 & 31.53 & 38.41 & 22.33 & 21.61 \\
\hline & Median & 56.19 & 43.95 & 110.00 & 96.26 & 156.72 & 137.43 \\
\hline & Range & $14.09-71.87$ & $19.44-70.36$ & $41.30-152.91$ & $42.04-174.08$ & 115.97-204.15 & $121.55-200.79$ \\
\hline \multirow[t]{4}{*}{ Repetitions } & $M$ & 0.03 & 0.02 & 0.02 & 0.02 & 0.00 & 0.00 \\
\hline & $S D$ & 0.02 & 0.03 & 0.02 & 0.02 & 0.01 & 0.01 \\
\hline & Median & 0.03 & 0.01 & 0.02 & 0.02 & 0.00 & 0.00 \\
\hline & Range & $.01-.06$ & $.00-.09$ & $.01-.06$ & $.00-.08$ & $.00-.02$ & $.00-.03$ \\
\hline \multirow[t]{4}{*}{ Pauses } & $M$ & 2.07 & 2.18 & 0.77 & 1.18 & 0.49 & 0.65 \\
\hline & $S D$ & 0.75 & 0.87 & 0.33 & 0.81 & 0.37 & 0.43 \\
\hline & Median & 2.18 & 2.11 & 0.73 & 0.87 & 0.41 & 0.66 \\
\hline & Range & $.69-2.92$ & $.90-3.75$ & $.20-1.50$ & $.12-2.71$ & $.11-1.13$ & $.00-1.5$ \\
\hline
\end{tabular}

Note. RP = Responsive Partner (i.e., communication partner demonstrating supportive backchannel responses); UP = Unresponsive Partner (i.e., communication partner demonstrating nonsupportive backchannel responses). 
Table 3. Organizational Structure of Themes, Subthemes, and Categories.

\begin{tabular}{|c|c|}
\hline Themes and subthemes & Categories \\
\hline \multicolumn{2}{|l|}{ I. PWA react negatively to unresponsive partners } \\
\hline \multirow{6}{*}{$\begin{array}{l}\text { A. PWA emphasized unresponsive behaviors and negative } \\
\text { judgments }\end{array}$} & 1. "I can't see the eyes" \\
\hline & 2. "Looking at her phone" \\
\hline & 3. Her introduction was very "sing-song" \\
\hline & 4. Poor "body language" \\
\hline & 5. "She just wasn't listening" \\
\hline & 6. She was "uptight" \\
\hline \multirow{2}{*}{$\begin{array}{l}\text { B. Control participants emphasized responsive behaviors } \\
\text { and positive judgments }\end{array}$} & 1. "She was smiling" \\
\hline & 2. "She was pleasant" and "encouraging" \\
\hline \multirow{4}{*}{$\begin{array}{l}\text { C. PWA experienced negative emotional reactions to } \\
\text { unresponsive partners }\end{array}$} & 1. "I was nervous" \\
\hline & 2. It was "frustrating" and "stressful" \\
\hline & 3. "I don’t want to talk to you" \\
\hline & 4. "I don't think it bothered me, I just noticed it" \\
\hline \multicolumn{2}{|l|}{$\begin{array}{l}\text { D. Control participants experienced few emotional } \\
\text { reactions to unresponsive partners }\end{array}$} \\
\hline \multicolumn{2}{|l|}{$\begin{array}{l}\text { II. Unresponsive partners affect the communication } \\
\text { experience }\end{array}$} \\
\hline \multicolumn{2}{|l|}{$\begin{array}{l}\text { A. "I don't know if that changed anything that I did" - } \\
\text { mixed behavioral reactions to unresponsive partners }\end{array}$} \\
\hline \multirow[t]{2}{*}{$\begin{array}{l}\text { B. PWA self-assessed their performance differently } \\
\text { depending on the story retell condition }\end{array}$} & $\begin{array}{l}\text { 1. PWA thought they did "very good" when } \\
\text { telling a story to a responsive partner }\end{array}$ \\
\hline & $\begin{array}{l}\text { 2. PWA gave a mixed self-assessment of a story } \\
\text { told to an unresponsive partner }\end{array}$ \\
\hline \multirow{4}{*}{$\begin{array}{l}\text { C. People with mild aphasia used intentional strategies to } \\
\text { cope with unresponsive partners }\end{array}$} & 1. Focus \\
\hline & 2. Getting it over with \\
\hline & 3. Big picture \\
\hline & 4. Rehearsal \\
\hline
\end{tabular}


Figure 1. Mean psychological stress ratings reported by each group across two conditions $(\mathrm{RP}=$ responsive partner condition; UP = unresponsive partner condition). Stress was rated on a 5-point Likert scale with higher scores indicating greater psychological stress. Mod = moderate aphasia group; Mild = mild aphasia group; Control = control group. Error Bars indicate standard error.

Supplemental Video S1. Responsive partner condition video example.

Supplemental Video S2. Unresponsive partner condition video example.

Supplemental Table S3. Correlations Between Apprehension Ratings and Psychological Stress, Story Retell Accuracy, and Story Retell Speed.

Supplemental Appendix S4. Interview Guide. 